\title{
No Better Time to Practice Open Science Than Now
}

Wikimedia GER Open Science Fellows Program

Harry Akligoh, Bsc. MPhil.

Open Bioeconomy Lab

Kwame Nkrumah University of Science and Technology

Kumasi Hive (Hive Biolab) 


\section{Outline}

William Kamkwamba's story and Open Science (OS) in Malawi

How Open Science influences my work

Bioeconomies in Africa

Open Science and COVID-19

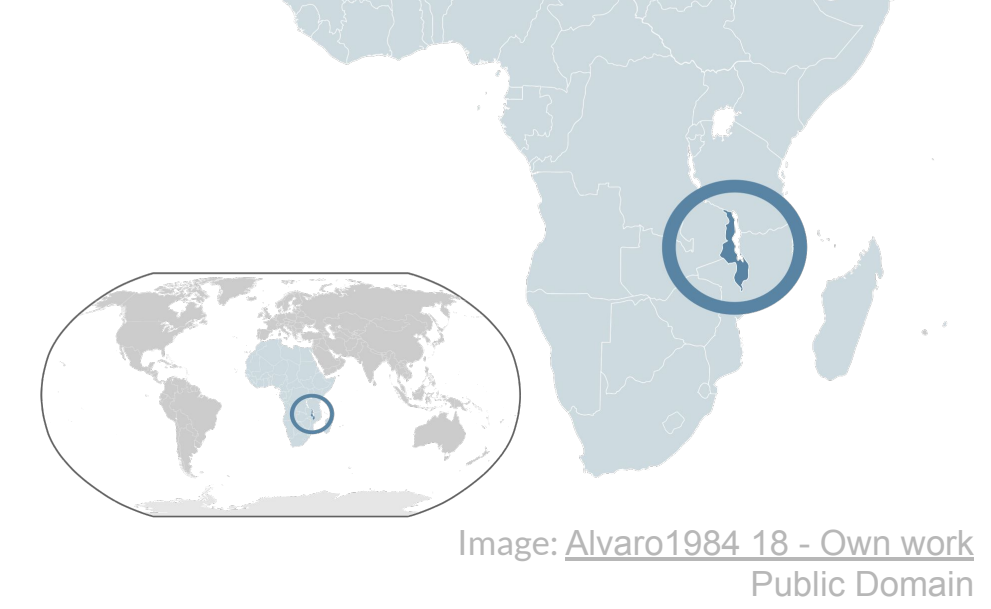

Open Science projects and initiatives disrupting the status quo 


\section{William Kamkwamba and Open Science}

Challenge: Water-scarcity due to drought

A 14 year old boy from Malawi

Applying the Principles of Open Science

To build an electricity-producing windmill

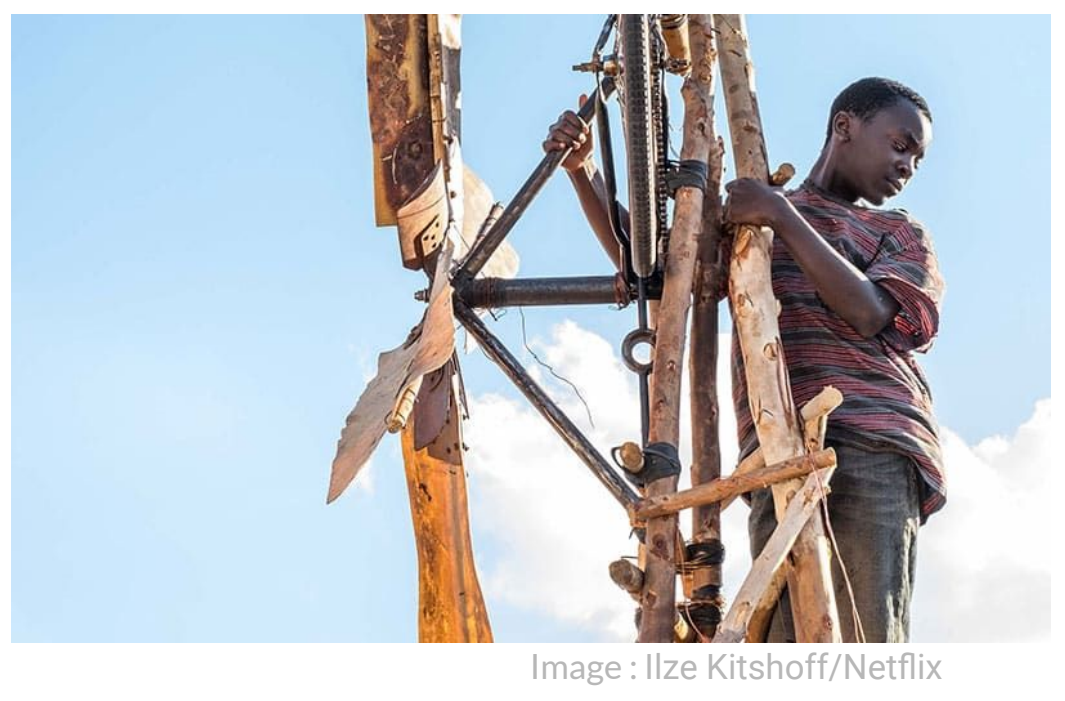




\section{Local challenges inspiring the use of OS in Africa}

A need for frugal innovation

Frugal technologies cannot be developed without Open Science

Applied OS principles:

Open Access

Open Hardware

Open Collaboration

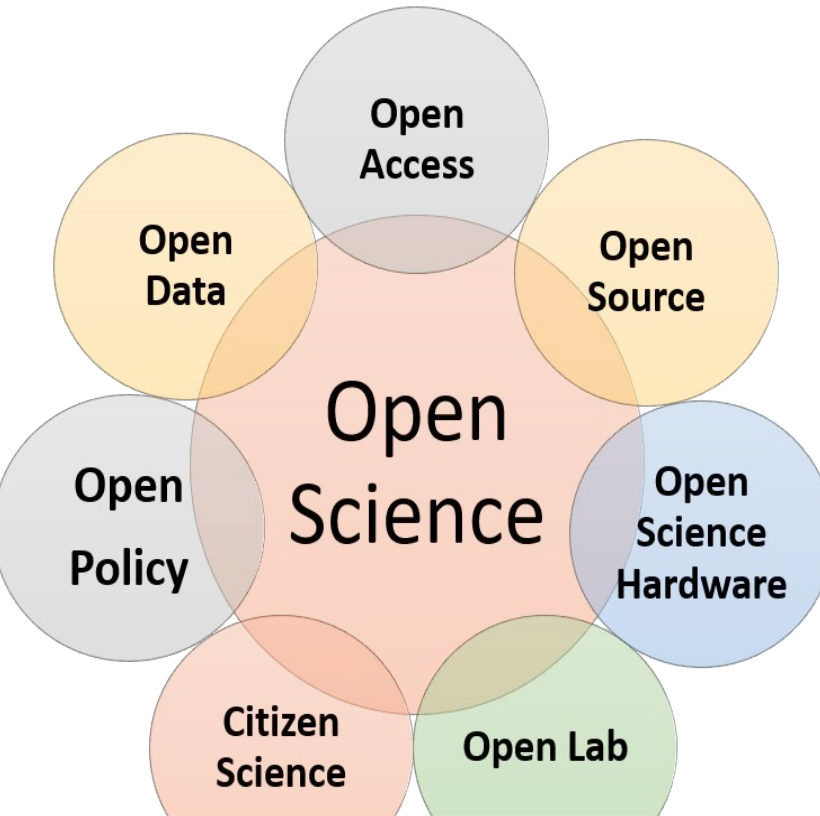




\section{Open Science in Africa}

\section{Lack of awareness \\ OS in Africa \\ African universities championing \\ paywalls}

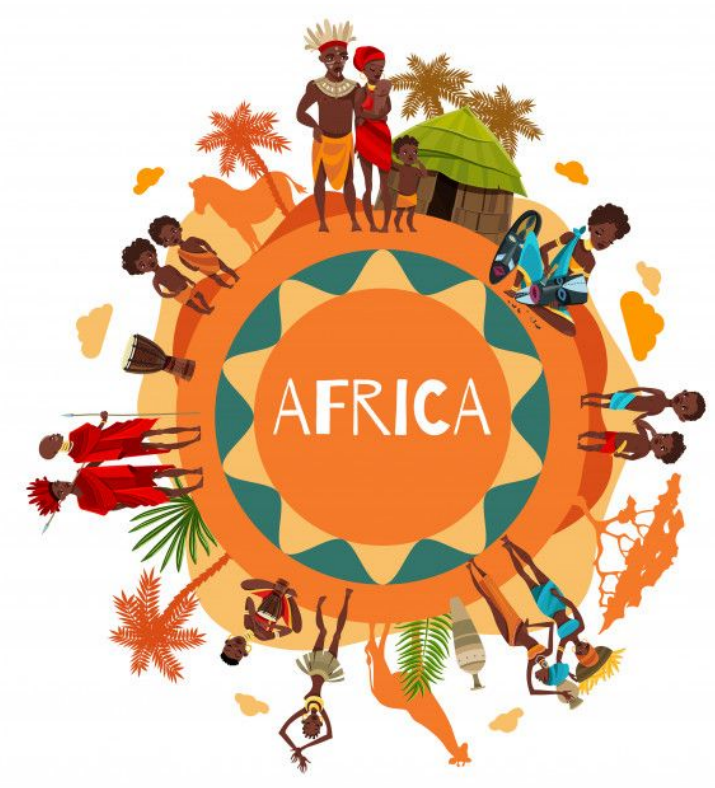

Image : freepik
Misconceptions about OS

OS = Free

Deprivation of ownership

What does OS entail 


\section{How Open Science influences my work}

everyday for the past 3-4 years.

In my formative years I was extensively involved in citizen science/ public engagement with science

Currently my work is at the interface of open technologies in biology and Open Science Hardware

My motivation to get into Open Science has largely been influenced by the word ACCESS

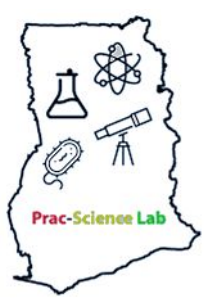

@prac_sciencelab

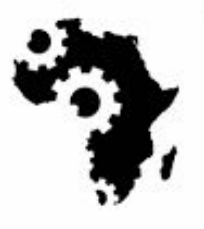

AFRICA OPEN SCIENCE HARDWARE

@AfricaOSH

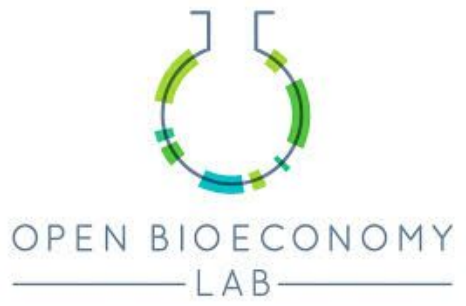

@openbioeconomy

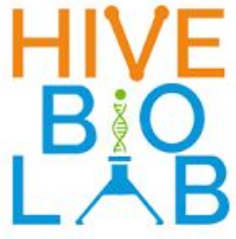

@hivebiolab

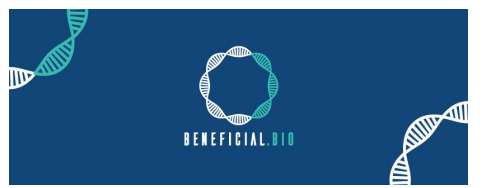

@beneficial.bio 


\section{My first Open Science Hardware at work}

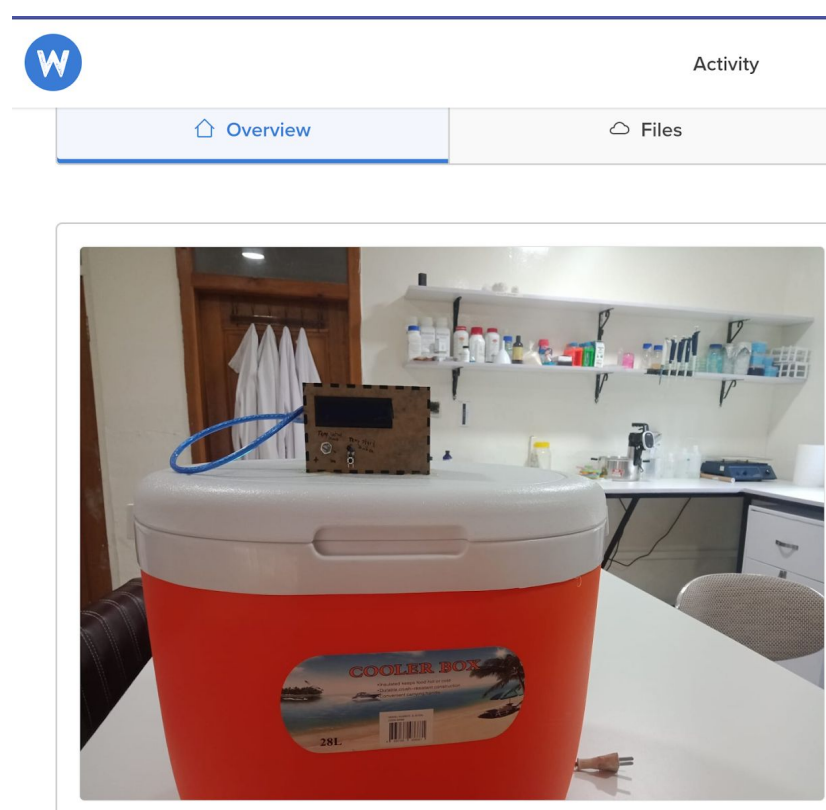

Discover

(Q)

的 Settings

\section{Incubator}

Incubators are useful piece of equipment, however, most of them are expensive to get in biohacking/diybio labs. The MboaLab in Cameroon through the Building Free Open Science Hardware by Andre Chagas built the first incubator which was adopted and built for use in Ghana. -

License

Last activity

Views

Contributions

Contributors

\section{CERN OHL}

12 May 2020 。

77

10

$\odot$

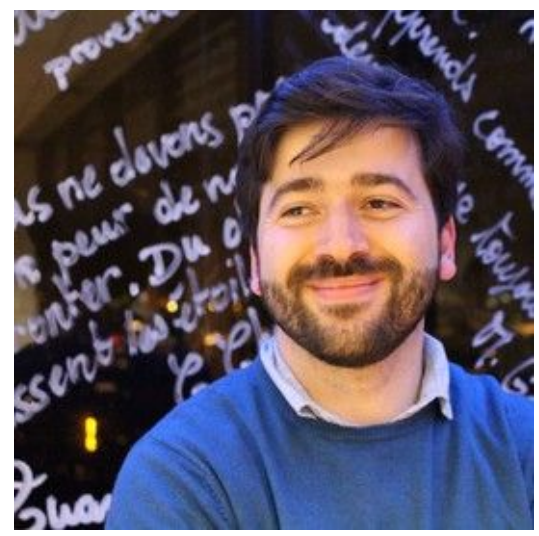

André Maia Chagas

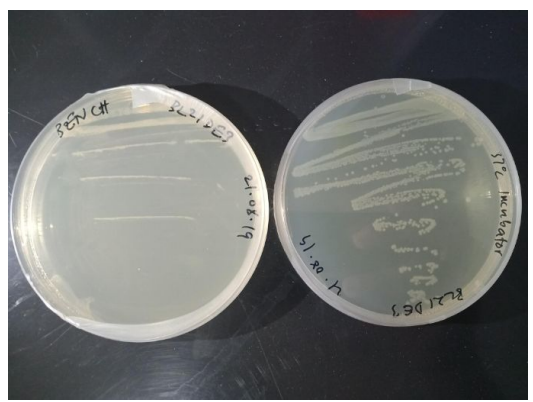


What do you think?

Does open mean free?

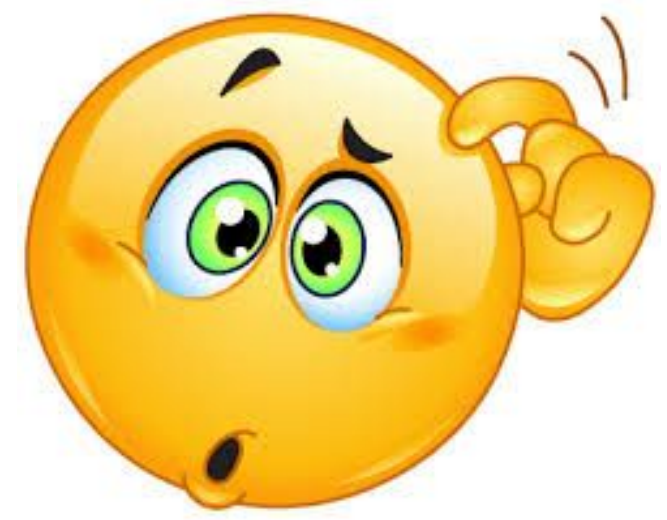




\section{Bioeconomies in Africa}

Africa has plenty of region-specific

bio-based resources incl. flora, fauna, microbes

Need to invest in infrastructure and laboratory resources for e.g. medicinal supply such as vaccines

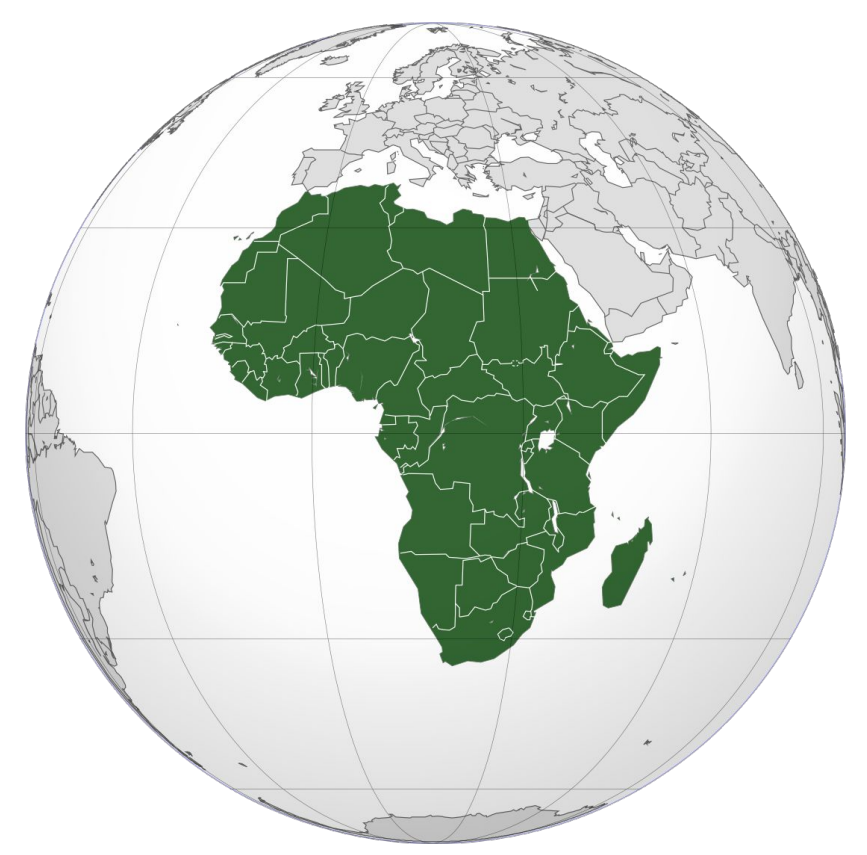




\section{Transforming Bioeconomies}

Biology is a manufacturing

technology capable of

transforming many African

economies into a self reliant and

sustainable one without over

dependence on foreign support.

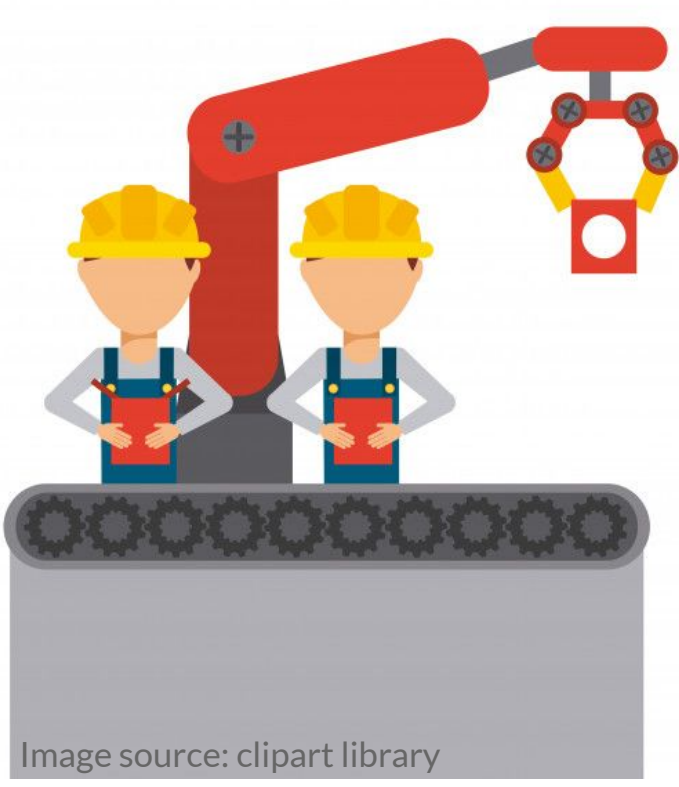




\section{Investment in African Bioeconomies}

Investments by African

governments and her development

partners have been biased towards

certain areas including the digital,

service and traditional agricultural

innovations to the neglect of her

innate bioeconomies.

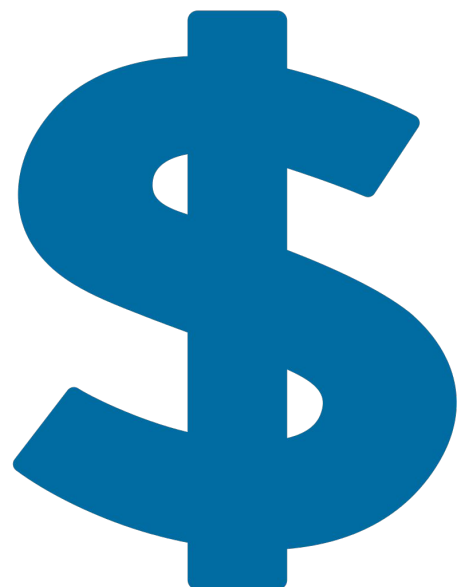

Image source: clipart library 


\section{What is lacking in Africa}

\section{NATIONAL BIOECONOMY BLUEPRINT}

"The world is shifting to an innovation economy and nobody does innovation better than America."

$$
\text { -President Obama, December 6, } 2011
$$

Economic activity that is fueled by research and innovation in the biological sciences, the "bioeconomy," is a large and rapidly growing segment of the world economy that provides substantial public benefit.' The bioeconomy has emerged as an Obama Administration priority because of its tremendous potential for growth as well as the many other societal benefits it offers. It can allow Americans to live longer, healthier lives, reduce our dependence on oil, address key environmental challenges, transform manufacturing processes, and increase the productivity and scope of the agricultural sector while growing new jobs and industries. 


\section{Changing narratives: Ethiopian Biotechnology Institute}

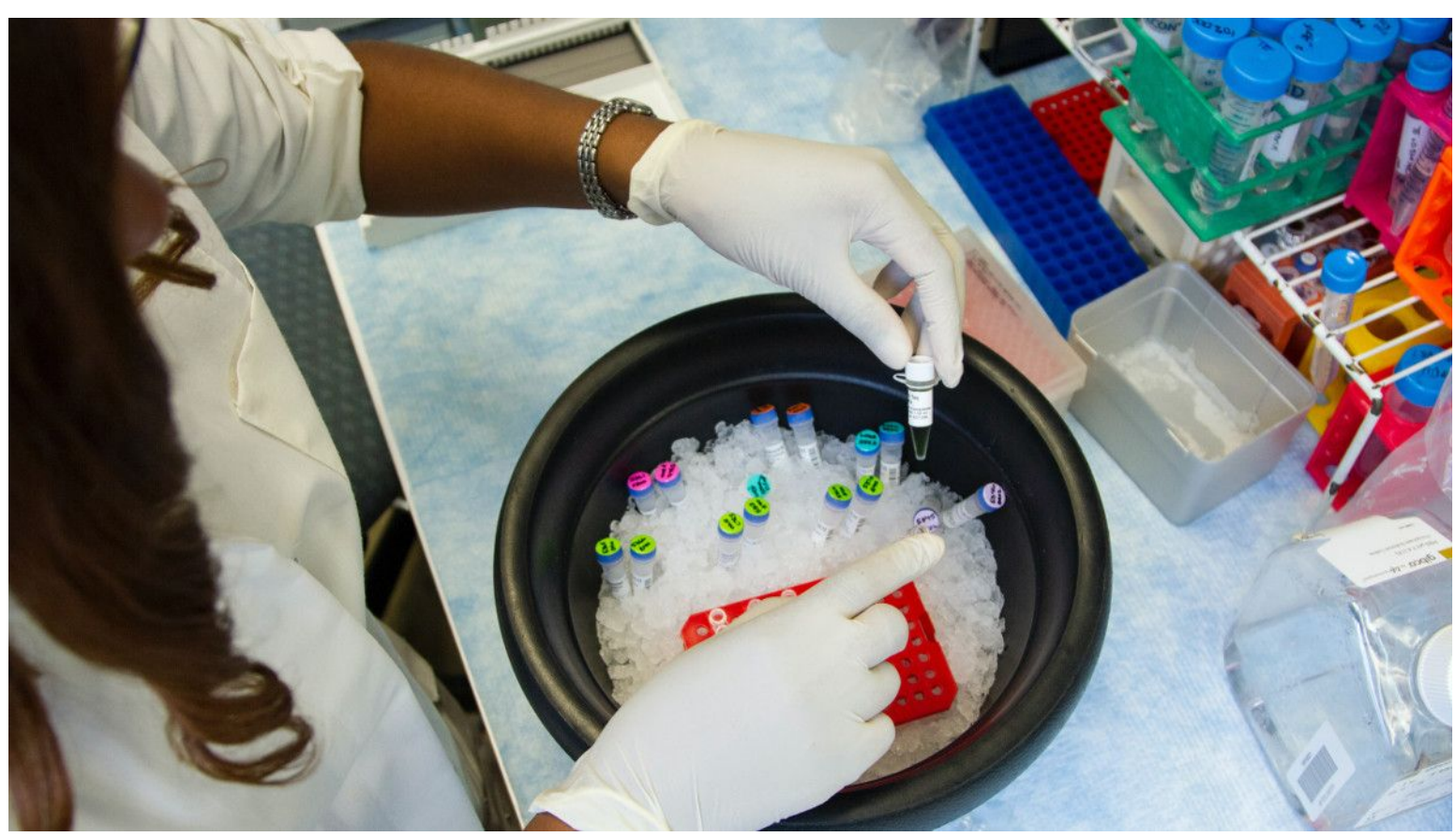

http://www.ebti.gov.et/biotechnology-center1

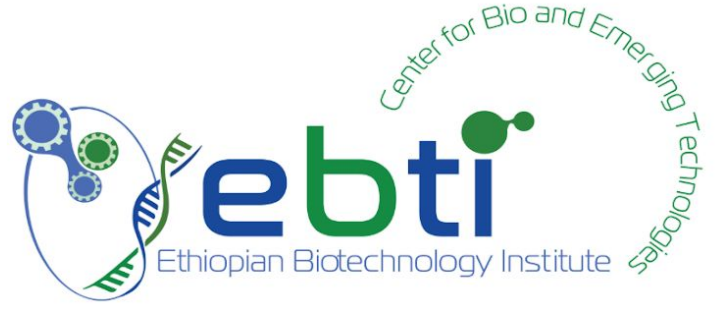

Visit us

Vision

Vision

To see product and services of biotechnology and emerging technologies utilize by our citizens as effective tools and innovative solution in their daily life. 


\section{Open Science and COVID-19}

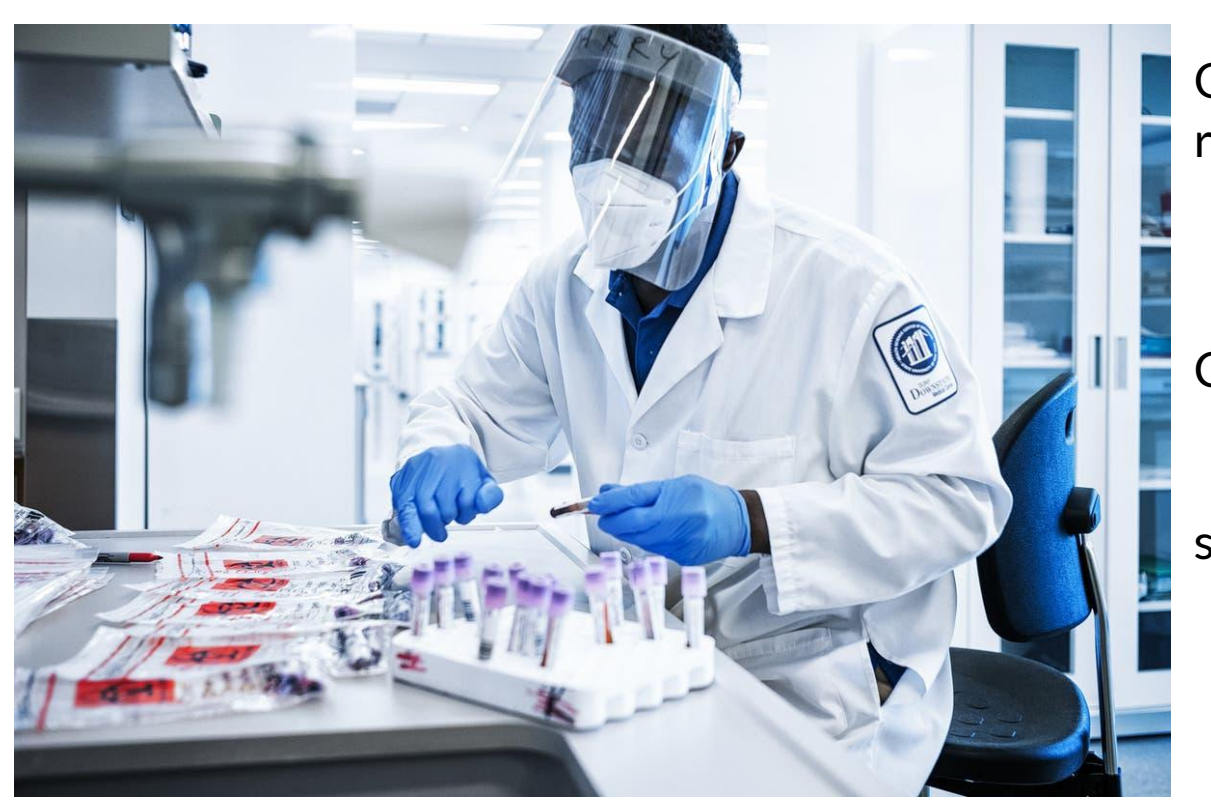

Overcoming the \#coronaviruspandemic requires;

Open Science; collective intelligence Better healthcare systems

Challenges

Loss of livelihood

Disrupted supply essential medical supplies

Weak healthcare systems 


\section{Open COVID Pledge}

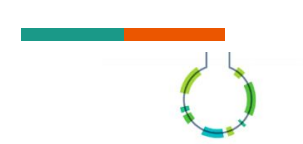

\section{OPEN \\ COVID \\ PLEDGE}

Open Bioeconomy Lab has supported the establishment of the Open COVID Pledge through Dr Jenny Molloy, who is a member of the Steering Committee that designed and rolled out the initiative.

The ethos of the Pledge is tightly aligned with the ideology of The Open Bioeconomy Lab. Projects operating in The Open Bioeconomy Lab that have escalated priority in these extraordinary times are the Open Enzymes Collection and the Public Domain Gazette; however, all projects run in the spirit of open science, collaboration, and sharing information. 


\section{Research in Diagnostics Collection}

Enable researchers globally to undertake research in diagnostic by producing their own reagents.

Genetic parts (plasmids, etc) Local biomanufacturing of COVID-19 diagnostic reagents Overcome reagent supply chain huddles

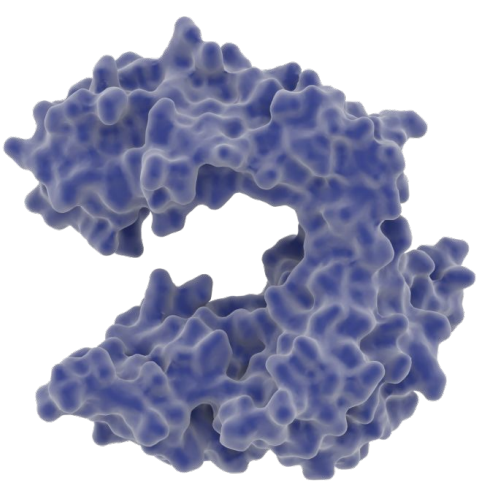

DNA Polymerase

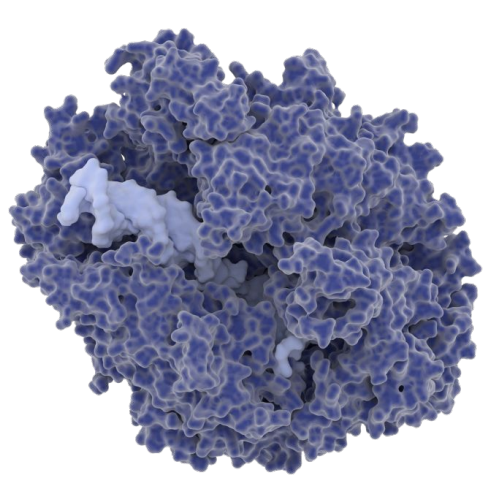

RNA Polymerase

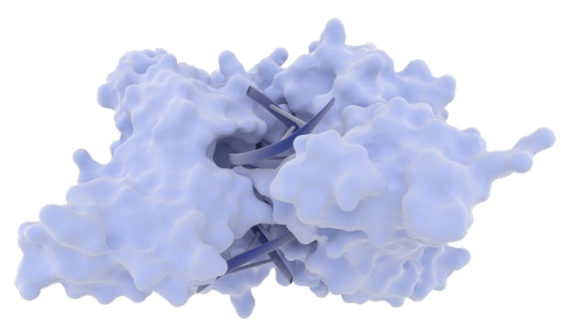

Restriction Enzyme 


\section{Reclone.org}

A global collaboration for equitable access to biotechnology

An open platform that enables scientists and researchers globally to share biological commons.

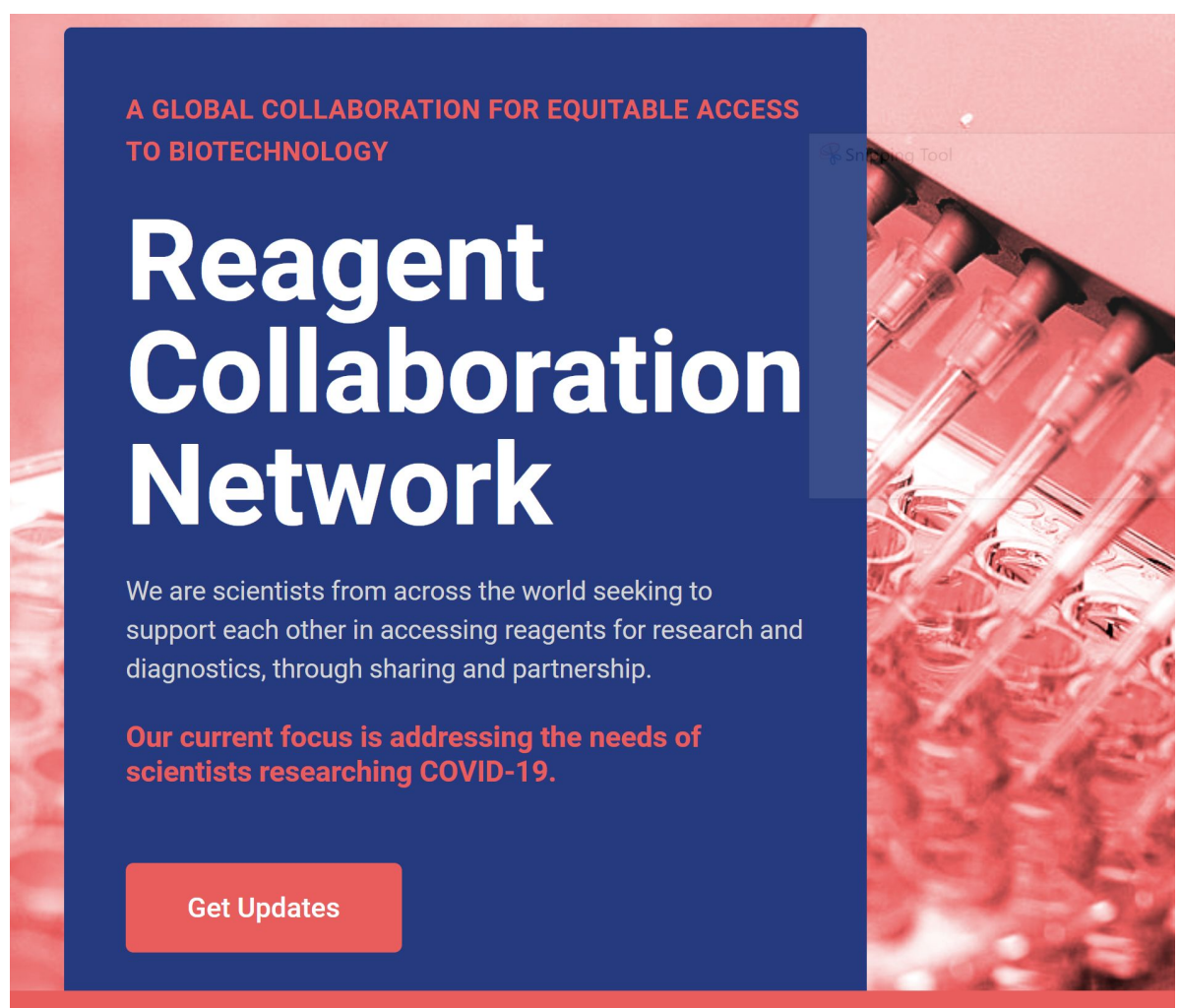




\section{Just One Giant Lab}

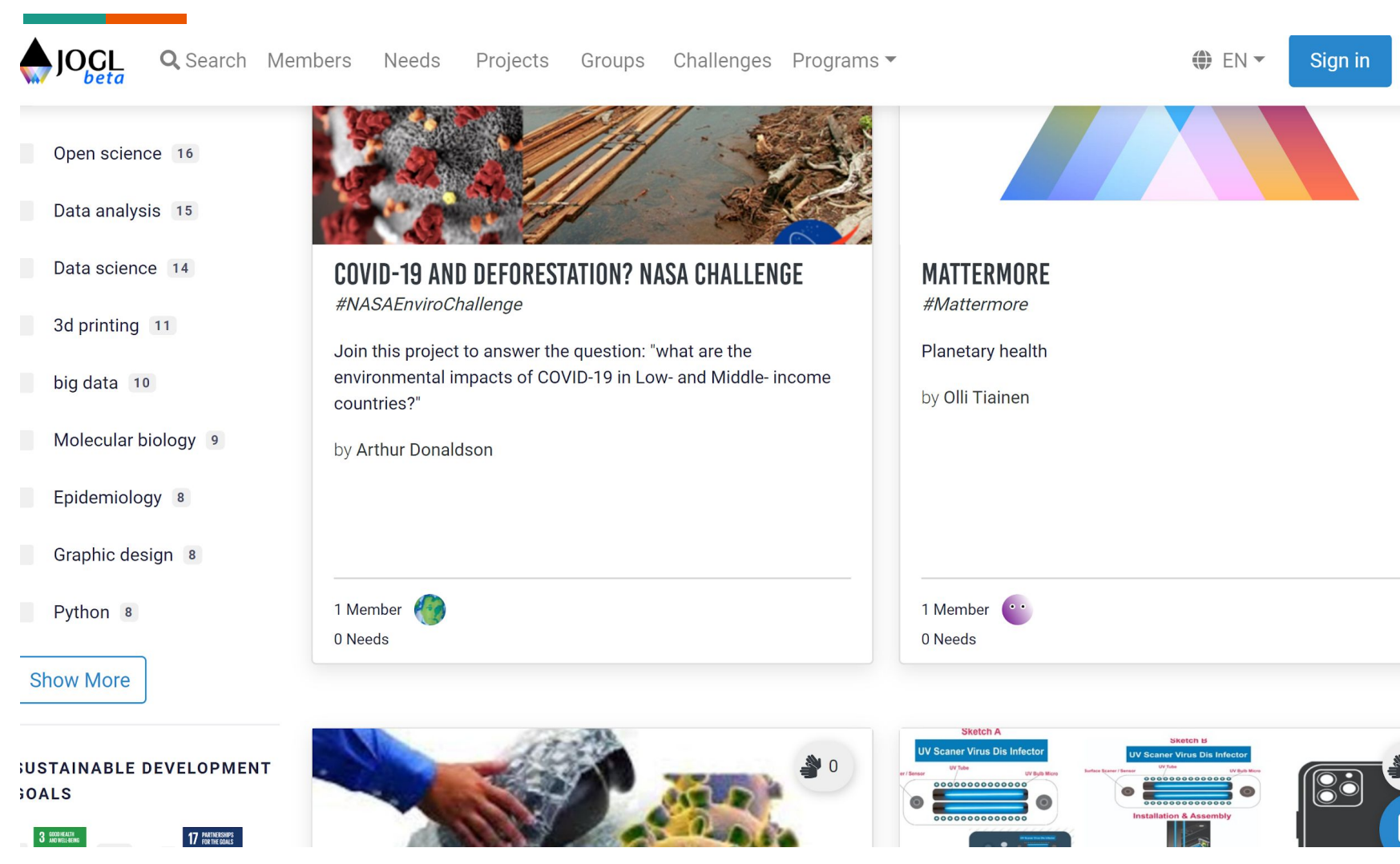




\section{AfricArXiV}

Afric

合 HOME - 出 SUBMIT - i COVID-19 (i) ABOUT - P PRINCIPLES

回 NEWS

$\square$ RESOURCES $\square$ CONTACT

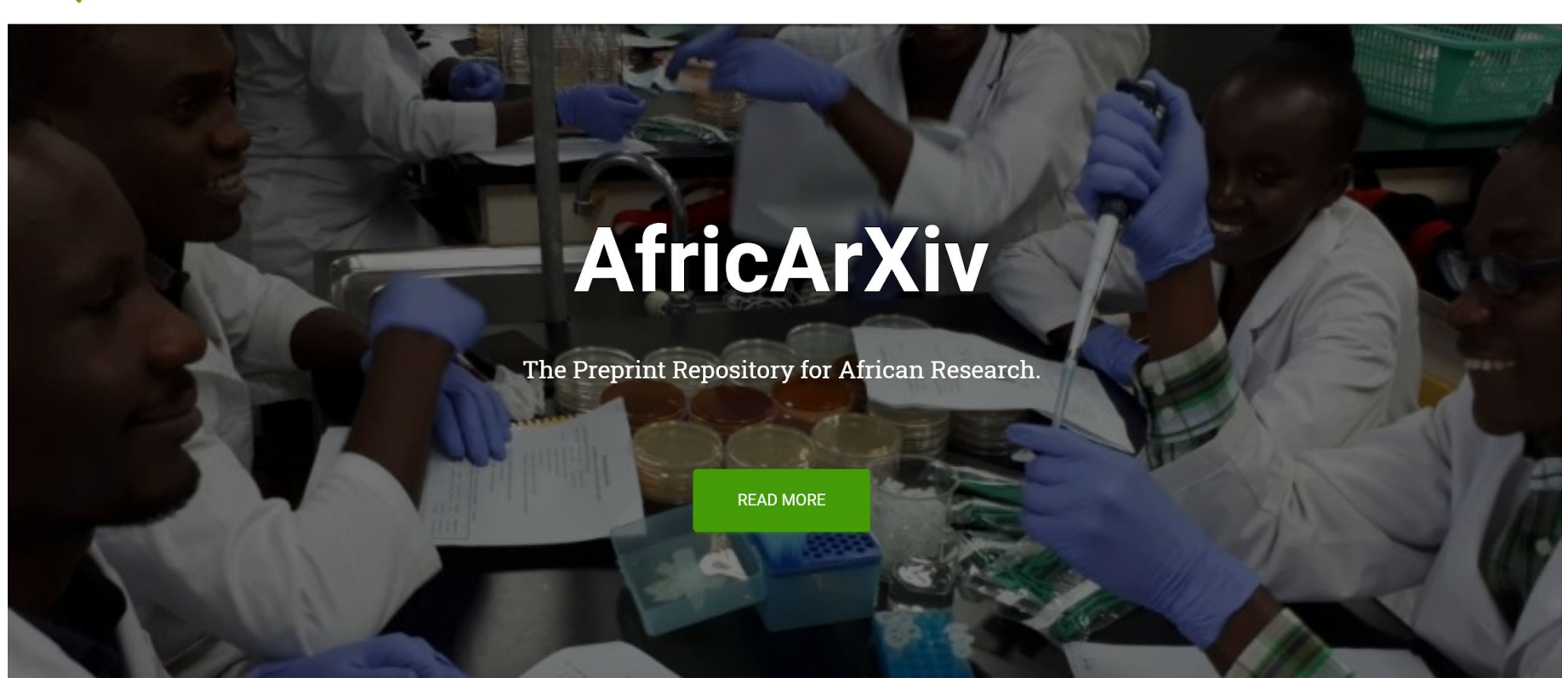




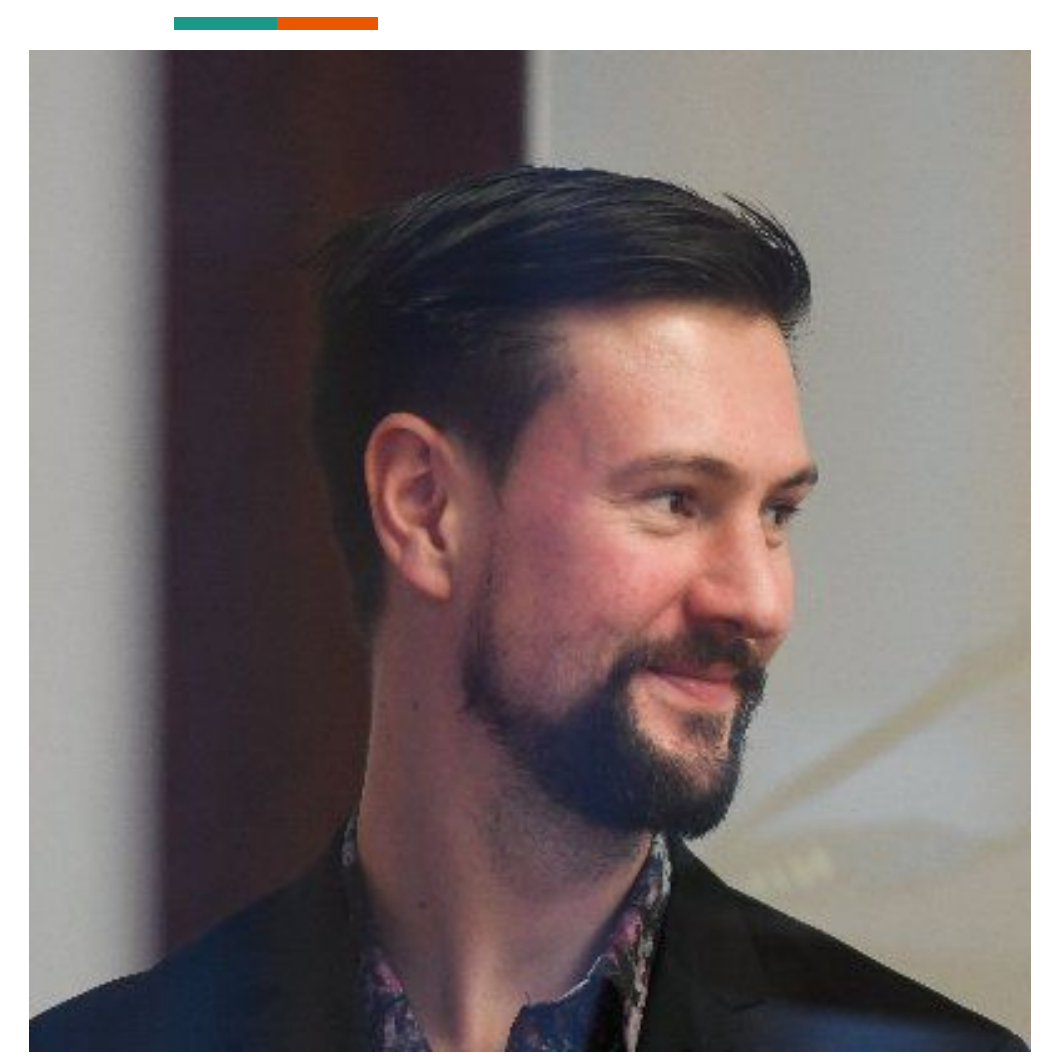

1

Adversity is always a teaching moment if we approach it with a healthy mindset. Be it online harassment and bullying, or a pandemic. Each moment is an opportunity for introspection. The more difficult and challenging it is, the more room for growth."

$\underline{\text { Jon Tennant }}$

Heroes Never Die. Rest well dear friend 


\section{Acknowledgment}
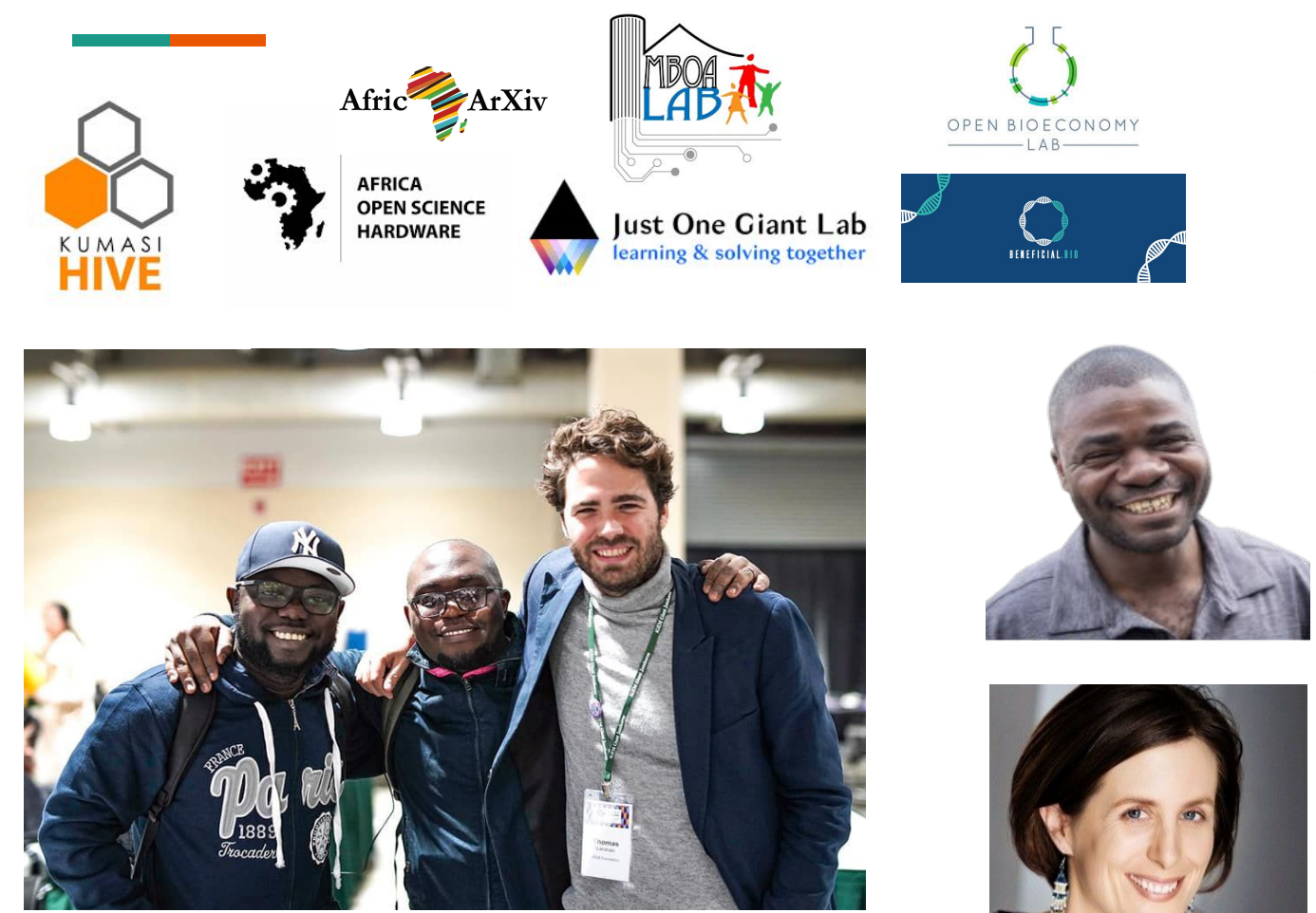

Thomas

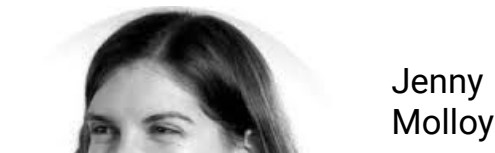

Jorge Appiah, Valerian Sanga, Thomas Landrian

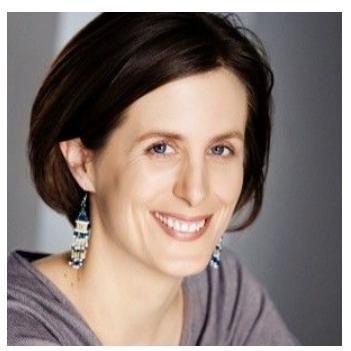

Johanna

Havemann

OPEN SCIENCE FELLOWS PROGRAM 


\section{No Better Time to Practice Open Science Than Now}

Ending notes and some call to action:

- The world needs OS now, more than ever and you are the agents to lead that change.

- If you're to lead a project in Africa on OS what will that be?

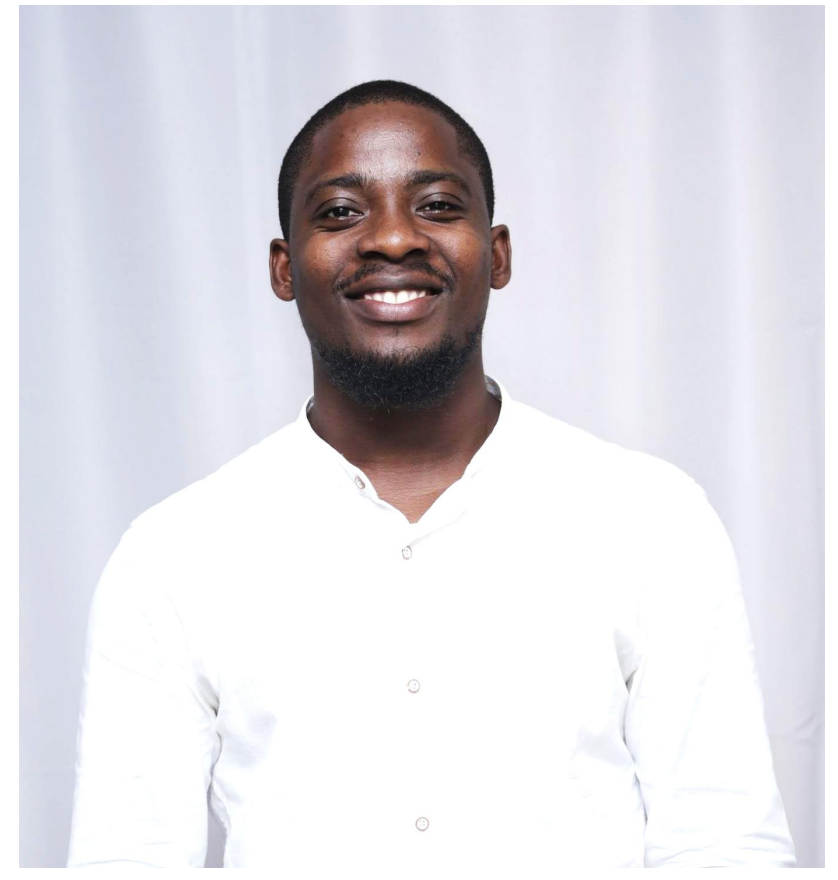

Twitter: @harryakligoh

Email: harryakligoh@gmail.com 